\title{
ИССЛЕДОВАНИЕ ПОЛУЧЕНИЯ ФОСФОРНОЙ КИСЛОТЫ И СЛОЖНЫХ УДОБРЕНИЙ ИЗ ФОСФОРИТОВ МЕСТОРОЖДЕНИЯ АЗЕРИ
}

В настоящей статье представлены результаты исследования процесса сернокислотной экстракции фосфорной кислоты (ЭФК) из фосфоритов Азери и переработки полученной ЭФК в аммофос и нитроаммофоску. Исследованные флотационные концентраты фосфорита Азери (7 обр.) различались по содержанию как $\mathrm{P}_{2} \mathrm{O}_{5}(23,5-30,1 \%)$, так и примесей (соединения магния, железа и др.). Подробная характеристика проб фосфорита приведена в ['].

Получение ЭФК. Использовался описанный ранее ${ }^{[2]}$ циклический метод имитации непрерывного процесса с трехкратной промывкой фосфогипса. Экстракция проводилась по дигидратному режиму, обычно при $75^{\circ} \mathrm{C}$; с двумя пробами фосфорита - также при $90^{\circ}$ (таблица). Количество серной кислоты составляло 100-107\% от стехиометрической нормы на осаждение кальция, продолжительность экстракции 5 ч, отношение жидкая фаза : твердая фаза (Ж: Т) $=2,5: 1$.

Показатели процесса экстракции во многом зависят от состава жидкой фазы пулыпы. С повышением содержания $\mathrm{P}_{2} \mathrm{O}_{5}$ до $15-20 \%$ наблюдалось улучшение основных показателей процесса: уменьшение пеновыделения при дозировке фосфорита, повышение степени извлечения

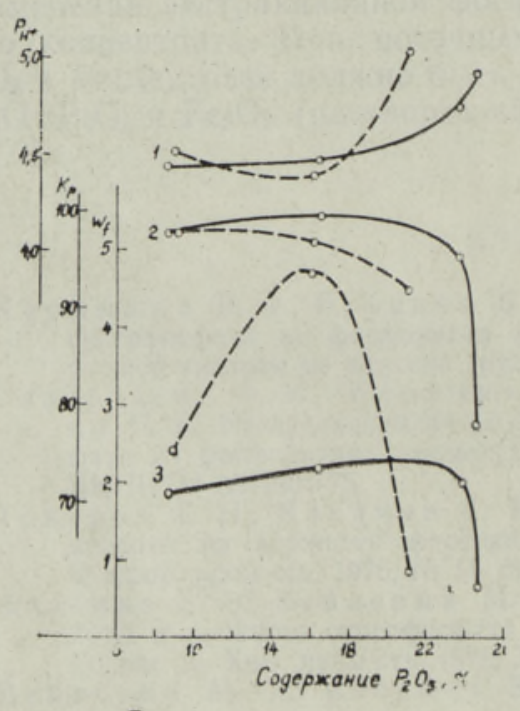
$\mathrm{P}_{2} \mathrm{O}_{5}$, увеличение скорости фильтрации при промывке фосфогипса и уменьшение влажности промытого фосфогипса.

Дальнейшее повышение концентрации ЭФК $(>15-20 \%)$ приводило к ухудшению извлечения $\mathrm{P}_{2} \mathrm{O}_{5}$ и уменьшению скорости фильтрации, а также к увеличению расходного коэффициента водородного иона кислоты.

Рис. 1. Изменение показателей процесса экстракции $\mathrm{H}_{3} \mathrm{PO}_{4}$ из фосконцентрата 7 в зависимости от содержания $\mathrm{P}_{2} \mathrm{O}_{5}$ в жидкой фазе при $75^{\circ} \mathrm{C}$ (сплошная линия) и $90^{\circ} \mathrm{C}$ (пунктир). $I$ - расход $\mathrm{H}^{+}$-иона на 100 г растворенного $\mathrm{P}_{2} \mathrm{O}_{5}\left(\mathrm{P}_{\mathrm{H}^{*}}\right), 2 ; 2-$ коэффициент разложения фосфорита $\left(\mathrm{K}_{\mathrm{p}}\right), \% ; 3$ - скорость фильтрации при промывке фосфогипса $\left(W_{f}\right), \mu^{3} / \mu^{2} \cdot \psi$. 


\section{Результаты экспериментов}

\begin{tabular}{c|c|c|c|c|c|c|c|c|c}
\hline \multirow{3}{*}{ Показатели } & \multicolumn{5}{|c|}{ Температура экстракции $75^{\circ} \mathrm{C}$} & \multicolumn{2}{c}{$9{ }^{\circ} \mathrm{C}$} \\
\cline { 2 - 9 } & \multicolumn{8}{|c|}{ Номер образца фосконцентрата } \\
\cline { 2 - 9 } & 1 & 2 & 3 & 4 & 5 & 6 & 7 & 6 & 7 \\
\hline 1 & 2 & 3 & 4 & 5 & 6 & 7 & 8 & 9 & 10 \\
\hline
\end{tabular}

\section{I. Получение ЭФК}

a) Средние данные по всем циклам

Норма $\mathrm{H}_{2} \mathrm{SO}_{4}, \%$ от стехиометрии на $\mathrm{CaO}$ Гипсовое число

Расходный коэффициент $\mathrm{H}_{2} \mathrm{SO}_{4}$ на 1 г растворенного $\mathrm{P}_{2} \mathrm{O}_{5}, 2$

Степень извлечения $\mathrm{P}_{2} \mathrm{O}_{5}$ $\%$

Скорость фильтрации прн промывке фосфогипса, $M^{3} / M^{2} \cdot 4$
Содержание гигроскопичной влаги в фосфогипсе, $\%$

Расходный коэффициент $\mathrm{H}^{+}$-иона на 100 г растворенного $\mathrm{P}_{2} \mathrm{O}_{5}$, c

Содержание, \%

\section{$\mathrm{P}_{2} \mathrm{O}_{5}$}

$\mathrm{H}^{+}$

Отношение масс

$\mathrm{MgO}: \mathrm{P}_{2} \mathrm{O}_{5}$

$\mathrm{SO}_{3}: \mathrm{P}_{2} \mathrm{O}_{5}$

$\mathrm{Fe}_{2} \mathrm{O}_{3}: \mathrm{P}_{2} \mathrm{O}_{5}$

Общая степень нейтрализащии, \%

$\begin{array}{rrrrrrrrr}107 & 103 & 100 & 102 & 102 & 104 & 103 & 100 & 100 \\ 1,35 & 1,37 & 1,39 & 1,38 & 1,44 & 1,46 & 1,45 & 1,44 & 1,44 \\ & & & & & & & & \\ 3,21 & 3,03 & 2,82 & 2,70 & 2,75 & 3,04 & 3,07 & 2,93 & 2,92\end{array}$

б) Данные при концентрации ЭФК $20 \% \mathrm{P}_{2} \mathrm{O}_{5}$

$\begin{array}{lllllllll}98,6 & 98,8 & 99,3 & 99,6 & 98,5 & 99,0 & 97,2 & 94,3 & 92,6\end{array}$

$\begin{array}{lllllllll}1,4 & 1,4 & 1,25 & 1,35 & 1,85 & 2,0 & 2,2 & 2,2 & 1,8\end{array}$

$\begin{array}{lllllllll}37,9 & 42,6 & 49,6 & 50,8 & 41,9 & 42,4 & 42,2 & 33,0 & 30,0\end{array}$

$\begin{array}{lllllllll}4,84 & 4,60 & 4,19 & 3,87 & 4,19 & 4,56 & 4,60 & 4,96 & 4,89\end{array}$

в) Состав ЭФК последнего цикла

$\begin{array}{lllllllll}23,6 & 24,2 & 24,9 & 26,1 & 26,0 & 25,6 & 24,7 & 21,4 & 21,0 \\ 0,348 & 0,371 & 0,388 & 0,372 & 0,381 & 0,370 & 0,393 & 0,262 & 0,274 \\ & & & & & & & & \\ 0,151 & 0,120 & 0,081 & 0,065 & 0,078 & 0,128 & 0,124 & 0,097 & 0,113 \\ 0,280 & 0,230 & 0,162 & 0,082 & 0,107 & 0,222 & 0,280 & 0,126 & 0,155 \\ 0,047 & 0,044 & 0,037 & 0,038 & 0,025 & 0,044 & 0,045 & 0,041 & 0,044 \\ 38,0 & 31,9 & 24,9 & 23,6 & 23,8 & 33,9 & 31,0 & 38,1 & 35,1\end{array}$

\section{II. Получение аммофоса}

Содержание в продукте,

$\%$

Усвояемый $\mathrm{P}_{2} \mathrm{O}_{5}$

Водорастворнмый $\mathrm{P}_{2} \mathrm{O}_{5}$

Азот

Сумма питательных ве-

ществ

Мольное отношение

$\mathrm{NH}_{3}: \mathrm{H}_{3} \mathrm{PO}_{4}$

$\begin{array}{rrrrrrrrr}42,3 & 45,0 & 49,1 & 51,4 & 50,7 & 45,5 & 45,1 & - & - \\ 36,0 & 41,6 & 44,3 & 46,8 & 45,7 & 41,3 & 40,4 & - & - \\ 11,0 & 11,5 & 12,6 & 12,0 & 11,7 & 11,4 & 11,2 & - & - \\ 53,3 & 56,5 & 61,7 & 63,4 & 62,4 & 56,9 & 56,3 & - & - \\ 1,31 & 1,32 & 1,33 & 1,18 & 1,17 & 1,28 & 1,29 & - & -\end{array}$

III. Получение нитроаммофоски

Характеристика образцов упаренной ЭФК

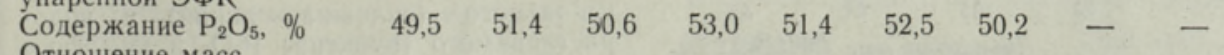

Отношение масс

$\mathrm{MgO}: \mathrm{P}_{2} \mathrm{O}_{5}$

$\begin{array}{lllllll}0,081 & 0,092 & 0,084 & 0,062 & 0,078 & 0,127 & 0,120\end{array}$ 


\begin{tabular}{|c|c|c|c|c|c|c|c|c|c|}
\hline 1 & 2 & 3 & 4 & 5 & 6 & 7 & 8 & 9 & 10 \\
\hline $\begin{array}{l}\mathrm{SO}_{3}: \mathrm{P}_{2} \mathrm{O}_{5} \\
\text { Содержание в продукте, } \\
\%\end{array}$ & 0,1 & 2 & 0,162 & 0,078 & 0,111 & 0,210 & 0,255 & - & - \\
\hline $\begin{array}{l}\text { Усвояемый } \mathrm{P}_{2} \mathrm{O}_{5} \\
\text { Водорастворимый } \mathrm{P}_{2} \mathrm{O}_{5} \\
\text { Водорастворимый } \\
\text { Водорастворимый } \mathrm{K}_{2} \mathrm{O}\end{array}$ & $\begin{array}{l}18,6 \\
17,3 \\
17,0 \\
20,0\end{array}$ & $\begin{array}{l}16,2 \\
15,2 \\
17,1 \\
16,9\end{array}$ & $\begin{array}{l}16,7 \\
15,8 \\
16,8 \\
17,9\end{array}$ & $\begin{array}{l}17,6 \\
16,5 \\
17,5 \\
18,8\end{array}$ & $\begin{array}{l}17,0 \\
16,0 \\
17,1 \\
17,3\end{array}$ & $\begin{array}{l}15,9 \\
15,3 \\
15,5 \\
18,4\end{array}$ & $\begin{array}{l}16,6 \\
15,9 \\
17,0 \\
16,2\end{array}$ & $\begin{array}{l}\overline{-} \\
\overline{-}\end{array}$ & $\begin{array}{l}\bar{z} \\
\overline{-}\end{array}$ \\
\hline $\begin{array}{l}\text { умма питательных ве- } \\
\text { цеств } \\
\text { лага }\end{array}$ & $\begin{array}{r}55,6 \\
0,2\end{array}$ & $\begin{array}{r}50,2 \\
0,6\end{array}$ & $\begin{array}{r}51,4 \\
0,3\end{array}$ & 0,2 & $\begin{array}{r}51,4 \\
0,3\end{array}$ & $\begin{array}{r}49,8 \\
1,3\end{array}$ & $\begin{array}{r}49,8 \\
1,1\end{array}$ & $\overline{-}$ & $\bar{z}$ \\
\hline
\end{tabular}

Особо значительное ухудшение показателей процесса наблюдалось в опытах с пробами фосфорита 6 и 7 при увеличении концентрации продукционной кислоты от 20 до $23-25 \%$ (рис. 1). Микроскопическим изучением кристаллов фосфогипса установлено, что ухудшение показателей процесса экстракции с повышением концентрации $\mathrm{H}_{3} \mathrm{PO}_{4}$ вызвано образованием скоплений из более мелких кристаллов гипса. Дополннтельные опыты с указанными пробами показали возможность улучшения фильтруемости фосфогипса проведением экстракции при повышенном отношении Ж: Т с одновременным снижением нормы $\mathrm{H}_{2} \mathrm{SO}_{4}$. Однако извлечение $\mathrm{P}_{2} \mathrm{O}_{5}$ при этом было более низким.

Экстракция $\mathrm{H}_{3} \mathrm{PO}_{4}$ при повышенной температуре $\left(90^{\circ}\right)$ способствовала улучшению фильтруемости фосфогипса при концентрации жидкой фазы до $20 \% \mathrm{P}_{2} \mathrm{O}_{5}$, но по извлечению $\mathrm{P}_{2} \mathrm{O}_{5}$ и расходу $\mathrm{H}^{+}$-иона кислоты наблюдалось ухудшение по сравнению с обычным температурным режимом (рис. 1).

Отмывка фосфогипса была практически полной во всех опытах. Содержание кристаллизационной воды в высушенном при $80^{\circ}$ фосфогипсе составляло $17-20 \%$, что приблизительно соответствует составу $\mathrm{CaSO}_{4} \cdot 2 \mathrm{H}_{2} \mathrm{O}$. Из примесей фоссырья фтор переходил в жидкую фазу обычно на $35-45 \%$, непиритное железо растворялось практически полностью (пирит не разлагается), а магний - на $80-95 \%$.

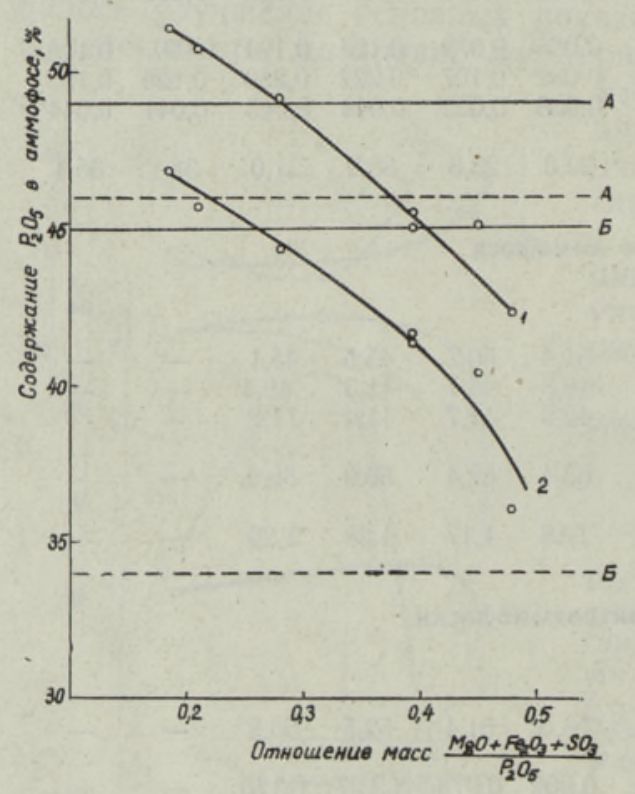

В пробах продукционной кислоты, содержащих $21-26 \% \quad \mathrm{P}_{2} \mathrm{O}_{5}$, отношение масс $\mathrm{Fe}_{2} \mathrm{O}_{3}: \mathrm{P}_{2} \mathrm{O}_{5}=$ $=0,025-0,05, \quad \mathrm{MgO}: \mathrm{P}_{2} \mathrm{O}_{5}=0,06$ 0,16 , а общая степень нейтрализации $\left[{ }^{2}\right]$ находилась в пределах $22-39 \%$. Наибольшая степень нейтрализации наблюдалась у образцов кислоты, полученных из концентратов с максимальным содержанием $\mathrm{MgO}$. ЭФК аналогичного качества возможно получить

Рис. 2. Зависимость качественных показателей аммофоса от содержания примесей в применяемой фосфорной кислоте. 1 и 2 - содержание, соответственно, усвояемого и водорастворимого $\mathrm{P}_{2} \mathrm{O}_{5}$ в опытных образцах аммофоса. Горизонтальные линии обозначают минимальное содержание усвояемого (сплошная линия) и водорастворимого (пунктир) $\mathrm{P}_{2} \mathrm{O}_{5}$ в аммофосе по ГОСТ 18918-73 для марок «А» и «Б». 
из фосфоритов месторождений Кингисепп, Чилисай, а также из фосфоритов Каратауского бассейна [3].

Получение аммофоса. Методика иоследования описана ранее [2]. В качестве сырья использовались образцы неупаренной ЭФК, полученные в обычном дигидратном режиме. Аммонизация ЭФК проводилась до $\mathrm{pH} 5$. Пробы готового порошковидного аммофоса (таблица), мало различались по содержанию азота, но наблюдались значительные колебания в содержаниях усвояемого и водорастворимого $\mathrm{P}_{2} \mathrm{O}_{5}$ : соответственно, $42-51$ и $36-47 \%$. Указанные колебания обусловлены различным содержанием в образцах как примесей железа и магния, вызывающих ретоградацию усвояемых форм $\mathrm{P}_{2} \mathrm{O}_{5}$ при аммонизации, так и связанного с магнием балластного сульфат-иона. Мольное соотношение $\mathrm{NH}_{3}: \mathrm{H}_{3} \mathrm{PO}_{4}$ в пробах аммофоса колебалось в диапазоне $1,17-1,33$, повышаясь с увеличением содержания примесей в ЭФК.

На основе проведенных экспериментов могут быть установлены требования к качеству исходной фосфорной кислоты и фосфорита. Для получения стандартного аммофоса марки «А» или «Б» (ГОСТ 18918-73) отношение массы примесей $\left(\mathrm{MgO}+\mathrm{Fe}_{2} \mathrm{O}_{3}+\mathrm{SO}_{3}\right)$ к массе $\mathrm{P}_{2} \mathrm{O}_{5}$ в ӘФК не должно превышать, соответственно, 20 и $40 \%$ (рис. 2), а для фосконцентратов (при экстракции $\mathrm{H}_{3} \mathrm{PO}_{4}$ по обычному дигидратному режиму) отношение примесей $\left(\mathrm{MgO}+\right.$ растворимый $\left.\mathrm{Fe}_{2} \mathrm{O}_{3}\right) \mathrm{K}_{2} \mathrm{P}_{5}-12$ и $17 \%$ (рис. 3).

Получение нитроаммофоски (НАФК). Был испробован вариант получения НАФК уравновешенного состава аммонизацией смеси фосфорной и азотной кислот. Использовались образцы ЭФК, полученные по обычному дигидратному режиму (см. выше) и упаренные до концентрации $49,5-53,0 \% \quad \mathrm{P}_{2} \mathrm{O}_{5}$. В процессе упарки происходило обесфторивание ЭФК на $50-80 \%$, а пробы упаренной кислоты при остывании загустевали. Аналогичное явление наблюдалось при упаривании ЭФК из каратауских фосфоритов, что было вызвано в основном осаждением фторида магния $\left[{ }^{4}\right]$. В наших экспериментах текучими при комнатной температуре оставались только пробы ЭФК, у которых отношение $\mathrm{MgO}: \mathrm{P}_{2} \mathrm{O}_{5}$ перед упаркой не превышало 0,08. Переработка этих проб после смешивания с $50 \%$-ной азотной кислотой протекала без особых затруднений. Использование сильно загустевших проб ЭФК стало возможным только после их ожижения методом механического смешения и подогрева до температуры $50-65^{\circ}$, а также при использовании более разбавленной (41\%-ной) азотной кислоты.

Аммонизация смеси кислот производилась газообразным

Рис. 3. Зависимость качественных показателей аммофоса от содержания примесей в исходном фосфорите. (Обозначения см. на рис. 2).

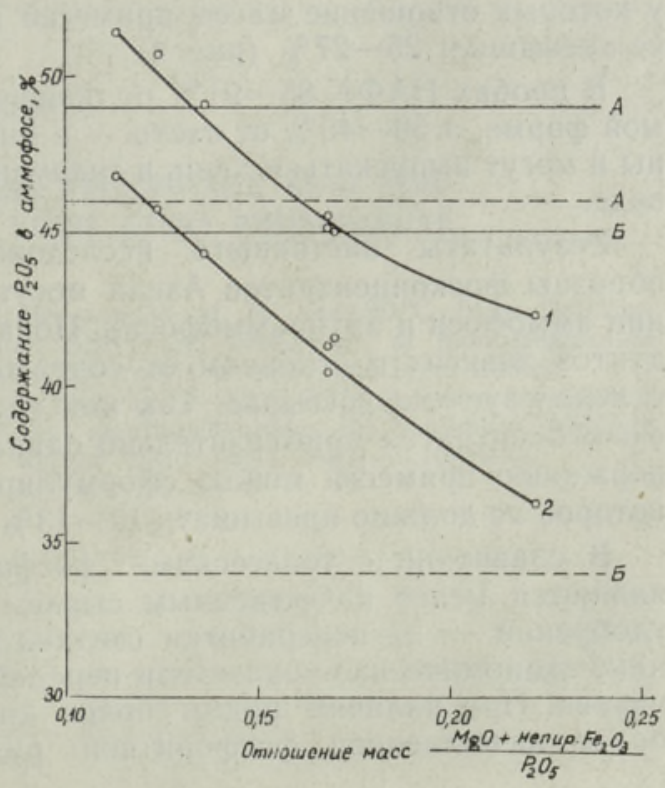




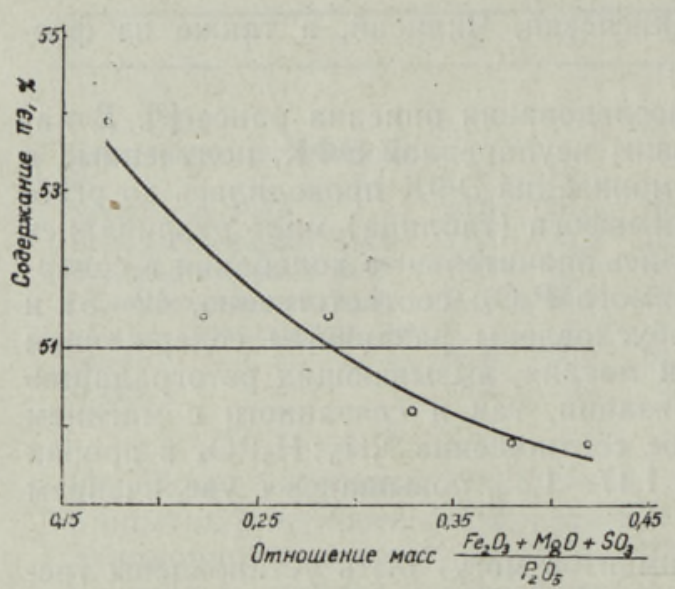

Рис. 4. Зависимость суммарного содержания питательных элементов (ПЭ) в нитроаммофоске от содержания примесей в применяемой фосфорной кислоте. Горизонтальной линией обозначено минимальное содержание ПЭ в нитроаммофоске по ГОСТ 19691-74.

аммиаком в реакторе, снабженном лопастной мешалкой, при поддерживании температуры пульпы $90^{\circ}$. Аммонизированная пульпа упаривалась на водяной бане до кашеобразной консистенции, добавлялся измельченный хлористый калий (частицы -0,5 мм ) и затем полученная масса высушивалась при температуре не более $90^{\circ}$.

Качество конечного продукта во многом зависит от степени аммонизации смеси кислот. Было установлено, что при аммонизации до рН 5 реакционная масса плохо сушится, сухой продукт трудно измельчается

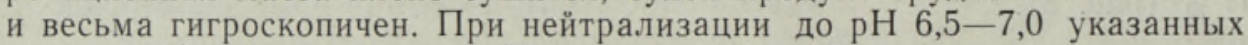
трудностей не наблюдалось. Поэтому в основной серии опытов проводилась аммонизация до данного $\mathrm{pH}$, с использованием смеси кислот с мольным отношением $\mathrm{N}: \mathrm{P}_{2} \mathrm{O}_{5}=1: 3$.

Результаты анализа проб готовой НАФК (таблица) показывают, что из всех проб упаренной ЭФК при соответствующем регулировании количества реагентов можно получать продукты, отвечающие требованиям ГОСТ 19691-74 по отдельным питательным веществам. Однако сумма питательных веществ в трех опытах, где пробы ӘФК в наибольшей степени были загрязнены балластным сульфатом магния, приблизительно на $1 \%$ (абс.) ниже требуемой стандартом. Получение стандартного продукта возможно только при использовании таких проб упаренной ЭФК, у которых отношение массы примесей (MgO, $\mathrm{Fe}_{2} \mathrm{O}_{3}$ и $\mathrm{SO}_{3}$ ) к массе $\mathrm{P}_{2} \mathrm{O}_{5}$ не превышает $25-27 \%$ (рис. 4 ).

В пробах НАФК 85-91\% от общего $\mathrm{P}_{2} \mathrm{O}_{5}$ находится в водорастворимой форме, а $30-40 \%$ от азота - в нитратной форме. Они гигроскопичны и могут выпускаться.лишь в гранулированном и кондиционированном виде.

Результаты настоящего исследования показывают, что лучшие образцы фосконцентратов Азери могут быть использованы при получении аммофоса и нитроаммофоски. Показатели процессов и качество продуктов зависят в основном от содержания примесей магния и железа в используемом фоссырье. Так как содержание растворимого железа в фосконцентратах приблизительно одинаково, то общее требование к содержанию примесей можно сформулировать по отношению $\mathrm{MgO}: \mathrm{P}_{2} \mathrm{O}_{5}$, которое не должно превышать $10-13 \%$.

В сравнении с тоолсескими фосфоритами, фосконцентраты Азери являются менее качественным сырьем для производства минеральных удобрений - их переработка связана с большими трудностями, а технико-экономические показатели переработки и качество продуктов более низкие. При наличии рядом более крупного месторождения Тоолсе с более качественной фосфоритной рудой использование фосфоритов 
Азери в ближайшее время представляется вряд ли целесообразным. Однако, поскольку у месторождения Азери имеются перспективы, необходимо проводить работы по более эффективному обогащению и облагораживанию этих фосфоритов.

\title{
ЛИТЕ РА Т У РА
}

1. А а с а м я э Э., В ейд е рм а М., Р е б а н е А. Исследование переработки фосфоритов месторождения Азери в двойной суперфосфат. - Изв. АН ЭССР. Хим., 1979 , т. 28 , № 3, c. $198-203$.

2. А а с а м я э Э. Э., В ей де рм а М. А., В ески м яэ Х. И. Получение экстракционной $\mathrm{H}_{3} \mathrm{PO}_{4}$ и аммофоса из термически обработанных фосфоритов бассейна Каратау. - Хим. пром-сть, 1974, № 10, с. $756-759$.

3. Соколов ски й А. А., У н а н я ц Т. П. Краткий справочник по минеральным удобрениям. М., 1977.

4. Позин М. Е., В аршавский В. Л., Одинцов Г. С., Вашкевич Н. Г. $\mathrm{K}$ вопросу о механизме загустевания магнийсодержащей фосфорной кислоты. В кн.: Технология минеральных удобрений. Л., 1977, с. 3-10.

Талличский политехнический институт

Поступила в редакцию $10 / \mathrm{XI} 1978$

E. AASAMÄE, M. VEIDERMA, Anne REBANE

\section{EKSTRAKTSIOONFOSFORHAPPE JA LIITVÄETISTE SAAMINE ASERI LEIUKOHA FOSFORIIDIST}

On käsitletud ekstraktsioonfosforhappe saamist dihüdraadimeetodil ning saadud happe töötlemist ammofossiks ja nitroammofoskaks. Ekstraktsiooniprotsess kulgeb normaalselt, kui $\mathrm{P}_{2} \mathrm{O}_{5}$ sisaldus produktsioonhappes ei ületa $20-22 \%$. Standardse ammofossi ja nitroammofoska saamiseks peab kasutatavas fosforiidikontsentraadis massisuhe $\mathrm{MgO}: \mathrm{P}_{2} \mathrm{O}_{5}$ olema alla $10 \%$.

\author{
E. AASAMAE, M. VEIDERMA, Anne REBANE
}

\section{OBTAINING WET-PROCESS PHOSPHORIC ACID AND COMPLEX FERTILIZERS FROM ASERI PHOSPHORITE}

Receiving phosphoric acid by the dihydrate process at 75 and $90^{\circ} \mathrm{C}$ from flotation concentrates of Aseri phosphorite (Estonian SSR) and production of monoammonium phosphate and NKP-fertilizer (nitroammophoska) from this acid have been studied.

The concentration of wet-process acid as high as $20-22 \% \quad \mathrm{P}_{2} \mathrm{O}_{5}$ has been established as optimal. For receiving conditional fertilizers mentioned above, the content of $\mathrm{MgO}$ in the phosphorite should not exceed the weight ratio $\mathrm{MgO}: \mathrm{P}_{2} \mathrm{O}_{5}=0.10-0.13$. 